\title{
SUPRA-AORTIC STENOSIS ASSOCIATED WITH MARFAN'S SYNDROME
}

\author{
BY \\ A. F. BURRY \\ From the Department of Pathology, Christchurch Hospital, New Zealand
}

The association of arachnodactyly with other skeletal abnormalities and with ocular and cardiac malformations is now well recognized, and numbers of cases illustrating the syndrome have been reported in recent years. The main cardiac malformations have been degeneration of the aortic media with dissecting aneurysm or aneurysmal dilatation, usually of the ascending aorta, but coarctation, changes in the pulmonary artery, atrial septal defect, and valvular lesions have also been described. The mitral valve is said to be affected more frequently but the aortic valve also may show thickening of the cusps. Aortic regurgitation is common, due to dilatation of the ring rather than to the valvular lesions. The following case is of interest in that Marfan's syndrome was accompanied by aortic stenosis of a type apparently not previously reported.

\section{Case Report}

A woman, aged 37, congenitally mentally defective, was first admitted to the Christchurch Hospital at the end of August, 1955, with signs of congestive heart failure of some three weeks' duration. She showed some features of Marfan's syndrome. She had long slender limbs, the characteristic facies, a high arched palate, a moderate kyphoscoliosis, and a myopic stare. She had a rapid thready pulse. The blood pressure was $150 / 125$, and later 130/110. The apex beat was in the seventh intercostal space at the mid-axillary line and there was other clinical evidence of gross left ventricular hypertrophy with also a suggestion of right ventricular enlargement. There was a triple rhythm on auscultation but no significant murmurs were detected. The neck veins were congested to the angle of the jaw, and there was sacral and ankle odema. Moist sounds were heard at both lung bases and the liver was enlarged four fingers below the costal margin. A chest X-ray confirmed a gross enlargement of the transverse diameter of the heart and showed evidence of moderate pulmonary vascular congestion. An electrocardiogram was interpreted as showing P-pulmonale, a vertical heart in clockwise rotation, sinus rhythm at 160 a minute, and ventricular extrasystoles. A blood count was normal and other investigations were normal.

The family history was unrevealing and no evidence of stigmata of Marfan's syndrome in other members of the family could be elicited on subsequent inquiry. Previous ophthalmological examination had shown a moderate myopia but no dislocation of the lenses of the eyes.

The cause of the cardiac enlargement remained in doubt. There were features against hypertension and aortic stenosis, the likely diagnoses, and a history of rheumatic fever was lacking. The patient's condition was improved considerably by full digitalization and she was discharged a month after admission without a firm diagnosis.

A week later she was readmitted to hospital gravely ill. She had been well until the morning of admission when she awoke complaining that her feet felt dead. She then complained of severe abdominal pain which wore off a little and then returned to spread and involve arms, legs, and chest. She became acutely dyspnœic with laboured bubbly respirations. On admission she was very cyanosed, sitting upright and struggling for breath. The extremities were cold and the pulse at the wrist was rapid and almost imperceptible. The blood pressure was 130/110. There was only slight sacral and ankle odema but the jugular venous pressure was raised and the liver still enlarged. The femoral pulses were absent, and both legs were cold and blue. Râles were widespread in both lungs. The abdomen was rigid, distended, and tympanitic, and bowel sounds were absent. Towards evening the patient started to vomit small amounts of brownish fluid. The respirations were bubbly and cyanosis persisted. She died 15 hours after the onset of pain. 
Necropsy. The body was that of a small middle-aged woman in a fair state of nutrition. The left pleural cavity contained $500 \mathrm{ml}$. of clear straw-coloured fluid and there were traces of fluid in the right pleural cavity and pericardial sac. The abdominal cavity contained watery blood-stained fluid.

The heart weighed $540 \mathrm{~g}$. and showed gross left ventricular hypertrophy. The left atrium was dilated. The left ventricular wall was thinned towards the apex where there was slight fibrosis of the myocardium and fibrosis of the endocardium to which masses of soft friable thrombus were adherent. There were small thrombi also in the right auricular appendage. The mitral, pulmonary, and tricuspid valves were normal. The coronary arteries showed atherosclerosis with many constrictions but no major occlusions.

The main interest of this case lies in the aorta which was grossly constricted at its origin by two valvular ridges above the aortic valves (which were present and normally formed). Viewed from above (Fig. 1) there

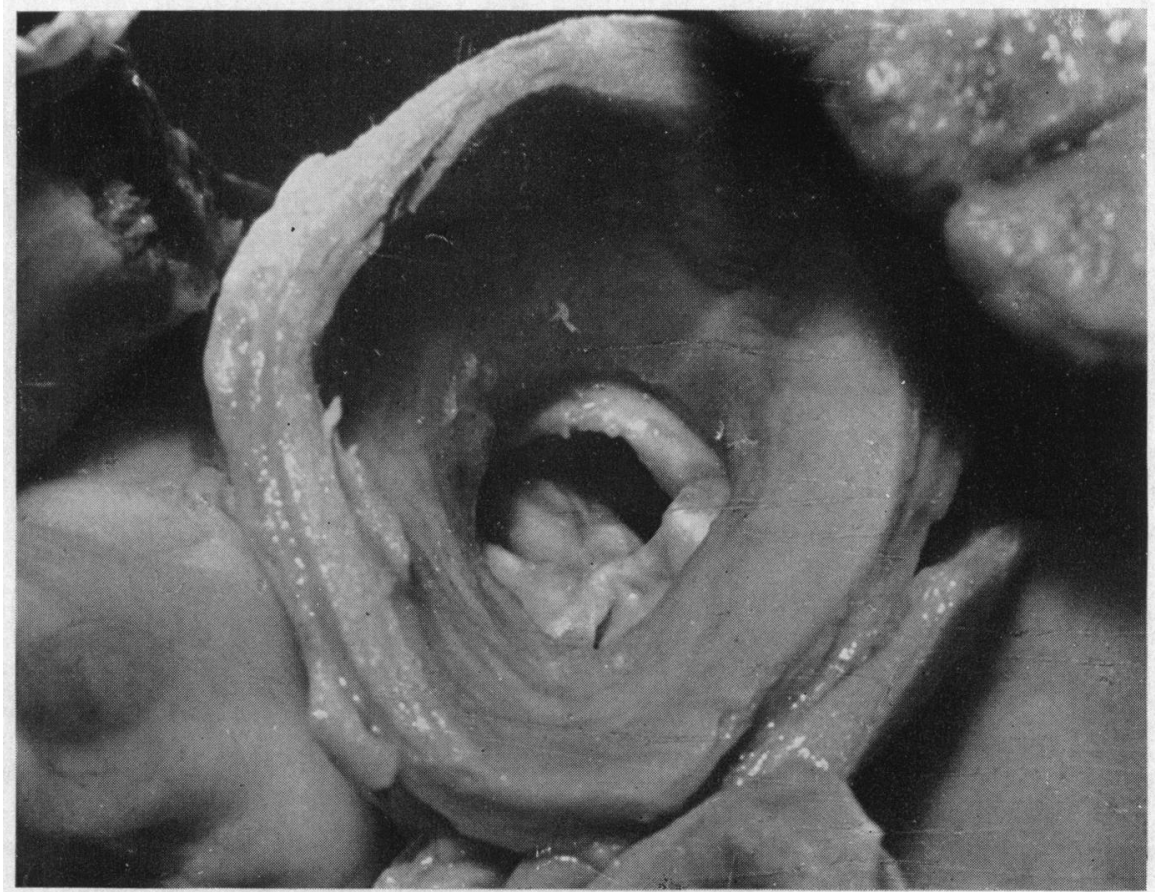

Fig. 1.-Abnormal valves viewed from above. Note marked constriction of aorta at valvular opening.

is seen to be a progressive expansion of the aorta from the point of constriction although at full calibre it appeared a little smaller than normal. The aortic wall was slightly thickened. The abnormal valves extended around the aorta immediately above the aortic valve commissures (Fig. 2) which fused with them. The aortic valves were of normal size but slightly thickened, and their margins were apposed by the constriction with consequent deepening of the sinuses of Valsalva, which formed deep pouches. In the depths of the sinuses the coronary arteries arose normally.

Microscopic Findings. Sections showed the abnormal valves to be composed of fibro-muscular tissue with rather scanty elastic fibres. Towards the free border there was hyaline collagenous tissue which included a small area of calcification. Applied to both upper and lower surfaces of the ridge were cushions of fibrous tissue thickening the intima and apparently derived from organization of thrombus. Sections of the aorta above the constriction showed slight thickening when compared with controls of similar age. The inner half of the media was deficient in elastic fibres and composed of rather loose fibromuscular tissue. No actual degenerative changes or medio-necrosis could be demonstrated.

Sections from the apex of the left ventricle showed the fibrosis to be mainly an endocardial thickening consisting of laminated fibrous tissue which merged with organizing thrombus of varying age. Deeply the myocardium was thinned with atrophy of many muscle fibres and replacement by hyaline fibrous tissue. 
Other Findings. The aorta contained a number of large emboli and smaller emboli were demonstrated occluding the superior mesenteric artery from just beyond its origin, the splenic and hepatic arteries, and both external iliac arteries. The lungs showed an early pneumonic reaction to inhaled vomitus. The stomach and upper small intestine were distended with fæculent fluid. The remainder of the jejuno-ileum was dark and necrotic from early infarction. The liver showed chronic venous congestion. The brain showed no striking abnormality macroscopically.

Post-mortem Diagnosis. Congenital supra-aortic stenosis. Endocardial thrombosis? on small infarct. Multiple embolism with infarction of small intestine. Inhalation of vomitus.

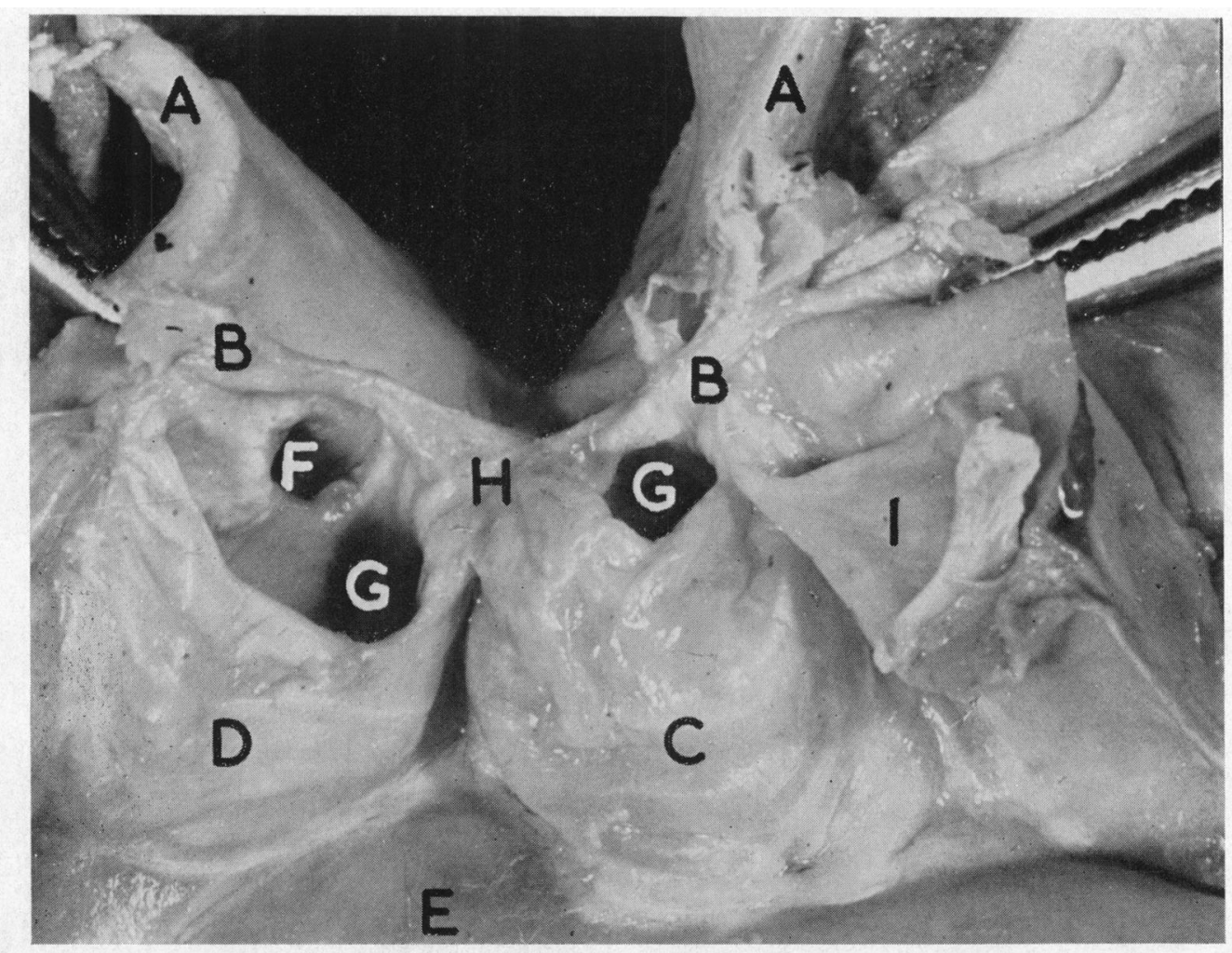

FIG. 2.-Opened specimen, showing from above down: (A) aortic wall; (B) abnormal ridges; (C) anterior and (D) left posterior aortic valve cusps; (E) upper left ventricular wall. On the left (F) the opening of the left coronary artery is well seen. Note deepening of sinuses of Valsalva $(G)$, and slight fusion of commissures which merge with the abnormal ridges at $(H)$. The right posterior aortic valve cusp (I) has been divided and partly removed.

\section{Comment}

Probable Sequence of Events. The gross stenosis of the aorta resulted in severe left ventricular hypertrophy. Heart failure may have been precipitated by a small infarct at the apex of the left ventricle although the area of muscle necrosis was very slight. The degree of endocardial fibrosis would suggest that organizing thrombus had been present for considerably longer than the two months which was the total duration of symptoms. The endocardial thrombosis may be the result of aortic stenosis alone and the myocardial fibrosis a secondary change. When a fragment of thrombus became dislodged it is possible that it became wedged in the constricted ventricular outlet initiating severe circulatory failure. Its sudden passage through the opening would cause a change in intraventricular pressure and would tend to dislodge further masses of thrombus.

Nature of the Malformation. The essential abnormality appears to be an infolding of the inner $\mathrm{L}$ 
aortic wall immediately above the aortic valve, with formation of two valvular ridges. It is difficult to postulate any origin for these appearances other than a congenital malformation. There is no evidence of rheumatic or other inflammatory process in the aortic valves proper. There is some resemblance to coarctation but, while coarctation distal to the usual site has been described, I can find no record of any proximal to the origin of the great vessels. The changes in the aortic media fall short of those classically associated with Marfan's syndrome but other clinical features justify the diagnosis. It seems likely that the aortic malformation is related to these changes in the media.

\section{Summary}

A case of Marfan's syndrome with a new aortic malformation is described. This abnormality consisted of a gross constriction of the aorta immediately above the aortic valve, with formation of two valvular ridges.

For permission to publish this case I have to thank Dr. F. O. Bennett under whose care the patient was admitted, and Dr. T. Morton, Medical Superintendent. I also wish to thank Dr. D. T. Stewart for help and advice in preparing this report. 